GU J Sci, Part C, 6(2): 259-268 (2018)

Gazi Üniversitesi
Fen Bilimleri Dergisi
PART C: TASARIM VE TEKNOLOJI
dergipark.gov.tr/http-gujsc-gazi-edu-tr

\title{
Duyarlı Tasarım ile Bir M2M Platformunun Gerçekleştirilmesi
}

\author{
Saadin OYUCU ${ }^{1,}$ Hüseyin POLAT ${ }^{2}$

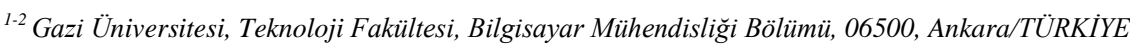

\begin{abstract}
Öz
Makale Bilgisi

Başvuru: 01/06/2017

Düzeltme: $24 / 07 / 2017$

Günümüzde giderek artan bir oranda makinelerin birbirleri ile iletişimde olduğu görülmektedir. Herhangi bir sektör için geliştirilen makineler arası iletişim (M2M: Machine to Machine) uygulamasının kullanıcı ile etkileşimi için bir M2M platformuna ihtiyaç duyulmaktadır. M2M platformunun amacı veri toplama, veri izleme, veri yönetimi ve raporlama-analiz gibi işlevleri sağlamaktır.
\end{abstract}

Kabul: 07/09/2017

Anahtar Kelimeler

M2M Platform

Duyarl Tasarim

Duyarll Web Arayüzleri

Keywords

M2M Platform

Responsive Design

Responsive Web Design
M2M platformları çoğunlukla web tabanlı olarak geliştirilir ve kullanıcının her ortamdan platforma erişim sağlaması hedeflenir. Bu hedef doğrultusunda bazı M2M platformları hem masaüstü hem de mobil uygulama sürümleri oluşturularak kullanıcıya sunulmaktadır. Fakat bu durum mobil işletim sistemi ve mobil ekran boyutuna göre farklı arayüz tasarımları yapmayı gerektirmektedir. $\mathrm{Bu}$ durum arayüz geliştiricilerinin işini oldukça zorlaştırmaktadır. $\mathrm{Bu}$ çalışmada her mobil işletim sistemi ve ekran boyutuna göre arayüz geliştirmek yerine duyarlı tasarıma sahip web tabanlı bir M2M platformu geliştirilmiştir. Bu sayede masaüstü, web ve mobil sistemler için ayrı ayrı M2M platform arayüzü hazırlanmasına gerek kalmamıştır. Hazırlanan M2M platform arayüzü masaüstü veya mobil web tarayıcılarında ekran boyutlarına göre dinamik şekillenerek sorunsuz şekilde kullanılabilmektedir.

\section{Development of an M2M Platform with a Responsive Design}

\begin{abstract}
Nowadays it has been clearly observed that machines are more and more communicating with each other. An M2M (Machine to Machine) communication application developed for any sector needs an M2M platfrom in order to interact with the user. The aim of an M2M platform is to fulfill the functions such as collecting data, tracking the data, data management, and reporting and analysis.

M2M platforms are mostly developed as web-based systems, and the user is aimed to connect in any environment to the platform. In this direction, some of the M2M platforms are released as both desktop and mobile applications. However, in such cases, there is a need to develop different interface designs for mobile operating systems and screen size. This issue makes the interface developers' job harder. In this study, the M2M platform is designed with a responsive interface rather than developing different M2M interface designs for every mobile operating system and screen size. Thanks to this responsive design, it is no longer needed to develop different interfaces for desktop, web, and mobile systems. The M2M platform interface developed in this study can be used comfortably with the dynamic feature shaped according to the desktop and mobile screen sizes through web browsers.
\end{abstract}

\section{GİRIŞ (INTRODUCTION)}

M2M, makineden makineye, makineden insana mobil veya başka terminallerle veri iletimi teknolojisini ifade etmektedir [1]. M2M platformlar ise M2M teknolojisine dayalı olarak geliştirilen ve farklı sektörlere hizmet veren uygulamaların yönetimini kolaylaştırmak için geliştirilen platformlardır [1]. Veri toplama, veri izleme, veri yönetimi ve raporlama-analiz gibi tüm yönetim gereksinimleri M2M 
platformlar sayesinde kullanıciya sunulmaktadır. Bu platformlar sayesinde M2M uygulamalarının işlevselliği artmaktadır.

Teknolojinin ilerlemesiyle mobil cihaz kullanıcılarının sayısı giderek artmıştır. Aynı şekilde mobil şebeke alt yapısı da sürekli olarak gelişmektedir. $\mathrm{Bu}$ nedenle mobil kullanıcıların internet kullanımı yaygınlaşmıştır. DailyTech istatistikleri mobil internet kullanıcılarının masaüstü kullanıcılardan daha fazla olduğunu göstermektedir [2]. Özellikle akıllı telefonların artması ile birlikte sayı ve çeşitlilik bakımından büyük bir büyüme oranı yakalayan mobil kullanıcı sayısı, kullanıcı dostu uygulamaların artmasını ve yaygınlaşmasını sağlamıştır.

Android, IOS ve Windows Phone mobil sistemlerde kullanılan başlıca işletim sistemleridir. Her işletim sistemi farklı ekran boyutları olan mobil cihazlara destek vermektedir. Ayrıca her işletim sistemi kendine özgü geliştirilen mobil web tarayıcısını kullanıcılara sunmaktadır. Bu mobil web tarayıcıların kendilerine has özellikleri bulunmaktadır. Aynı şekilde Chrome, Firefox, Internet Explorer, Safari, Opera, YaBrowser vb. birçok masaüstü web tarayıcı yazılımı mevcuttur. Kullanıcı bu tarayıcıları kullanarak istediği web sayfasına rahatlıkla ulaşabilmektedir.

Günümüzde artık sadece masaüstü web kullanıcılarını değil mobil web kullanıcılarının varlı̆ğ da göz önünde bulundurarak uygulamalar geliştirilmelidir. Geliştirilen web sayfası veya uygulamalarının farklı tarayıcılarda farklı görümüne sahip olacağı bir gerçektir. Sabit çözünürlük değeri ile tasarlanan ve yalnızca tek bir web tarayıcısı üzerinde test edilen web uygulaması, test edildiği web tarayıcısında sorunsuz çalışabilir fakat farklı tarayıcılarda görünümde bozulmalar olacaktır. Bu durumun en büyük nedeni ise web tarayıcıların her birinin desteklediği kod yapısı ve çalışma biçiminin farklı olmasıdır. Fakat gelişen kodlama teknikleri bize yeni yaklaşımlar sunmaktadır. Bu yaklaşımlardan biri olan duyarlı tasarım (Responsive Design) yaklaşımı hem web tabanlı uygulama geliştiricilere hem de kullanıcılara oldukça önemli kolaylıklar sağlamaktadır.

Duyarlı tasarım, herhangi bir web sayfasındaki görünümü net bir şekilde ayarlamak için kullanılan bir yöntemdir [3]. Bu yöntemin kullanıldığı bir web sayfasında, ekran çözünürlüğü veya ekran boyutu ne olursa olsun görünümler net bir şekilde sağlanabilmektedir. Duyarlı tasarım ile mobil cihazlarda ekranı büyütme veya küçültme gereksinimi ortadan kalkmaktadır. Çözünürlüğü farklı olan web tarayıcılarında ise sağa-sola kaydırma çubuklarını kullanmadan net bir şekilde görünüm elde edilebilmektedir. Duyarlı tasarım yöntemi kullanılarak geliştirilen bir web uygulaması, açıldığı cihazın ekran boyutu ve çözünürlüğune göre kendi görünüm özelliklerini dinamik bir şekilde değiştirmektedir. Bu yöntemle geliştirilen web sayfa veya uygulamaları sayesinde mobil işletim sistemleri için geliştirilmesi gereken ayrı ayrı mobil uygulama gereksinimleri ortadan kalkmaktadır. Herhangi bir şekilde internete bağlanan bir cihaz ve herhangi bir web tarayıcısı duyarlı tasarıma sahip bir web uygulamasının düzgün bir şekilde görüntülenip kullanılması için yeterlidir.

\subsection{Literatürde Duyarlı Tasarım Çalışmaları (Responsive Design Studies in Literature)}

Mohorovičić S. 2013 yılında yapmış olduğu gelişmiş internet sayfalarının duyarlı tasarımla gerçekleştirilmesi çalışmasında duyarlı tasarımın önemine değinmiş ve istatiksel sonuçlara yer vermiştir[4]. Jiang W. ve arkadaşları, duyarlı tasarım üzerine uygulama geliştirdikleri 2014 yılındaki çalışmalarında Bootstrap ve gerçek zamanlı medya aktarım düzeni için sorguların nasıl kullanılması gerektiği üzerinde durmuşlardır [5]. Yang Y. ve arkadaşları 2011 yılınlda M2M tabanlı konumlama ve izleme sistemi için duyarlı olmayan iletişim ara yüzü tasarımı yapmışlardır. Bu çalışma inşaat makinelerinin izlenmesi için gerçek hayatta uygulamaya konulmuştur. M2M'e dayalı terminaller ve kontrol merkezi arasındaki iletişim çalışmalarının etkin bir performans sergilediği görülmüştür [1]. Baturay M. ve Birtane M. 2016 yılında duyarlı web tasarımı kullanarak web tabanlı eğitim sistemi geliştirmişlerdir [6]. Böylelikle istenilen her noktadan düzgün ve net bir şekilde uzaktan eğitimi gerçekleştirmişlerdir. Hughes C. ve arkadaşları 2015 yılında kişiselleştirilmiş alt yazılar için duyarlı tasarım çalışması yapmışlardır [7]. Bu çalışmalarında video içerikleri ile birlikte alt yazılar göstererek yeni bir yaklaşımı açıklamaya çalışmışlardır. Baytürk M. ve arkadaşları 2013 yılında internet tabanlı olarak gerçekleştirdikleri sera otomasyon sisteminde yönetimi kolaylaştırmak adına duyarlı tasarıma sahip olmayan web arayüzleri hazırlamışlardır [8].

Doukas C. Ve Maglogiannis I. 2011 yılında giyilebilir algılayıcı verilerini bulut yapısında kullanmış ve bu verileri izlemek için duyarlı tasarıma sahip olmayan bir M2M web arayüzü geliştirmişlerdir [9]. İlgili 
çalışmalar incelendiğinde birçok M2M platformu geliştirilmeye çalışıldığ 1 görülmüştür. Farklı haberleşme teknolojileri ve web servisler ile geliştirilen M2M platformları duyarlı tasarıma sahip olacak şekilde gerçekleştirilmemiştir [10-14]. Duyarlı tasarım web sayfalarının kullanılabilirliğini arttırmaktır. Bazı kullanılabilirlik çalışmaları incelendiğinde farklı metotlar altında kullanılabilirlik değerlendirmeleri yapıldığı görülmüştür [15-16]. Fakat bu çalışmalarda duyarlı tasarıma sahip olup olmadığı kullanılabilirlik değerlendirilmesine alınmamıştır.

İlgili çalışmalara bakıldığında çeşitli alanlarda duyarlı tasarımın uygulandığı görülmektedir. Fakat duyarlı tasarımın uygulandığı çalışmaların sayısı oldukça azdır. M2M platformlar da ise duyarlı tasarımın uygulandığ 1 çalışmalara literatürde rastlanılmamıştır.

$\mathrm{Bu}$ çalışmada, öncelikle gerçek dünyadaki verilere dayanılarak, istatistiksel olarak duyarlı tasarımın önemi açıklanmıştır. Ayrıca duyarlı tasarım yaklaşımı uygulanarak bir M2M platform arayüzü gerçekleştirilmiştir. Gerçekleştirilen M2M platform arayüzünün masaüstü ve mobil web tarayıcıları ile kullanımı test edilerek başarılı sonuçlar elde edilmiştir.

\section{DUYARLI TASARIMIN ÖNEMİ (IMPORTANCE OF RESPONSIVE DESIGN)}

$\mathrm{Bu}$ çalışma kapsamında gerçek dünyadaki web sayfalarına hangi işletim sistemi, hangi web tarayıcı ve ne kadarlık bir çözünürlüğe sahip sistemlerden erişildiği tespit edilmeye çalışılmıştır. Bu tespit işlemi için Google Analytics ve Google Web Yönetici Araçları kullanılmıştır. Google Analytics, web sayfalarına erişimlerin istatistiki olarak incelenmesine yarayan bir araçtır [17]. Bu çalışma kapsamında istatistiksel analiz için gerekli veriler, erişimi 1400'ün üzerinde olan ve farklı sektörlere ait 4 adet web sayfasından alınmıştır. Verilerin alındığı web sayfalarının tümü duyarlı tasarıma sahip web sayfalarıdır. Türkiye kaynaklı olan web sayfalarının İngilizce dil desteği mevcuttur. Türkiye kaynaklı seçilen web sayfalarına sadece Türkiye'den değil dünya genelinden de erişimin sağlandığı görülmüştür. Tablo 1'de inceleme altına alınan 4 web sayfasına hangi işletim sisteminden kaç kişinin erişim sağladığı görülmektedir.

Tablo 1. Değişik işletim sistemlerinden web sayfalarına yıllık erişim sayıları (the number of different operating systems to yearly access web pages)

\begin{tabular}{|l|l|l|l|l|}
\hline İşletim Sistemi & 1. Web Sayfasi & 2. Web Sayfasi & 3. Web Sayfas1 & 4. Web Sayfas1 \\
\hline Macintosh & 586 & 962 & 828 & 767 \\
\hline Windows & 761 & 796 & 459 & 1544 \\
\hline Android & 7 & 418 & 63 & 15 \\
\hline iOS & 9 & 195 & 35 & 18 \\
\hline Linux & 2 & 10 & 9 & 3 \\
\hline Windows Phone & - & 4 & 1 & 1 \\
\hline Diğer & 95 & 107 & 22 & 34 \\
\hline Toplam Giriş & 1460 & 2492 & 1417 & 2382 \\
\hline
\end{tabular}

Tablo 1'de görüldüğü gibi her web sayfasına farklı işletim sistemini kullanan cihazlardan erişim sağlanmıştır. Bu işletim sistemlerinden bazıları mobil işletim sistemleridir. İşletim sistemlerindeki bu farklılık giriş sayılarına da yansımaktadır. Şekil 1, 2, 3 ve 4'te bu web sayfalarına erişimin hangi web tarayıcılarından yapıldığı grafiklerle gösterilmektedir.

Şekil 1, 2, 3 ve 4'te görüldüğü gibi web sayfalarına erişim farklı web tarayıcıları ile gerçekleştirilmektedir. Bu farklılık ülkeden ülkeye ve web sayfasının kullanım amacına göre değişiklikler göstermektedir. Ayrıca kullanılan web tarayıcının desteklediği Basamaklı Stil Şablonlarının(CSS: Cascading Style Sheets) özellikleri, web tarayıcı sürümüne göre farkl1lıklar göstermektedir. Bu durum farklı CSS özelliklerine sahip web sayfalarının farklı web tarayıcılarında görünümünün bozulmasına neden olmaktadır. Örneğin Microsoft firmasının web tarayıcısı olan "Internet Explorer" un desteklemediği bazı CSS özellikleri tablo 2'de gösterilmektedir. 


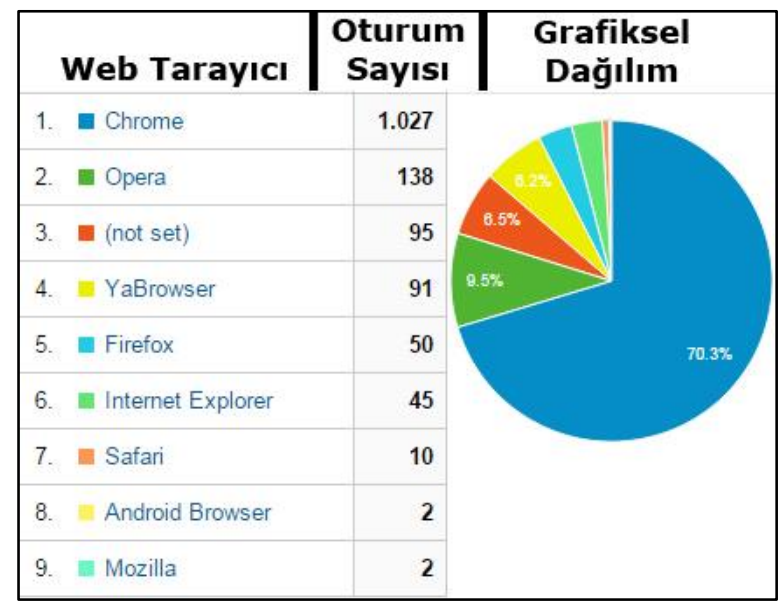

Şekil 1. "I" Numaralı web sayfasına erişimde kullanılan web tarayıcıları

\begin{tabular}{|c|c|c|}
\hline Web Tarayıcı & $\begin{array}{c}\text { Oturum } \\
\text { Sayısı }\end{array}$ & $\begin{array}{c}\text { Grafiksel } \\
\text { Dağılım }\end{array}$ \\
\hline 1. Chrome & 1.640 & \\
\hline 2. $=$ Safari & 217 & \\
\hline 3. Android Browser & 178 & \\
\hline 4. $=$ Firefox & 106 & \\
\hline 5. Internet Explorer & 100 & \\
\hline 6. (not set) & 90 & \\
\hline 7. $=$ Opera & 66 & \\
\hline 8. $=$ YaBrowser & 56 & \\
\hline 9. $\equiv$ Opera Mini & 20 & \\
\hline
\end{tabular}

Şekil 2. "2" Numaralı web sayfasına erişimde kullanılan web tarayıcıları

\begin{tabular}{|c|c|c|}
\hline Web Tarayıcı & $\begin{array}{c}\text { Oturum } \\
\text { Sayısı }\end{array}$ & $\begin{array}{c}\text { Grafiksel } \\
\text { Dağılım }\end{array}$ \\
\hline 1. Chrome & 1.223 & \\
\hline 2. Internet Explorer & 68 & \\
\hline 3. Safari & 40 & \\
\hline 4. $\equiv$ Firefox & 37 & \\
\hline 5. $=$ (not set) & 22 & \\
\hline 6. Android Browser & 14 & \\
\hline 7. YaBrowser & 5 & \\
\hline $\begin{array}{l}\text { 8. Mozilla Compatible } \\
\text { Agent }\end{array}$ & 3 & \\
\hline 9. 1 Opera & 3 & \\
\hline
\end{tabular}

Şekil 3. "3” Numaralı web sayfasına erişimde kullanılan web tarayıcıları 


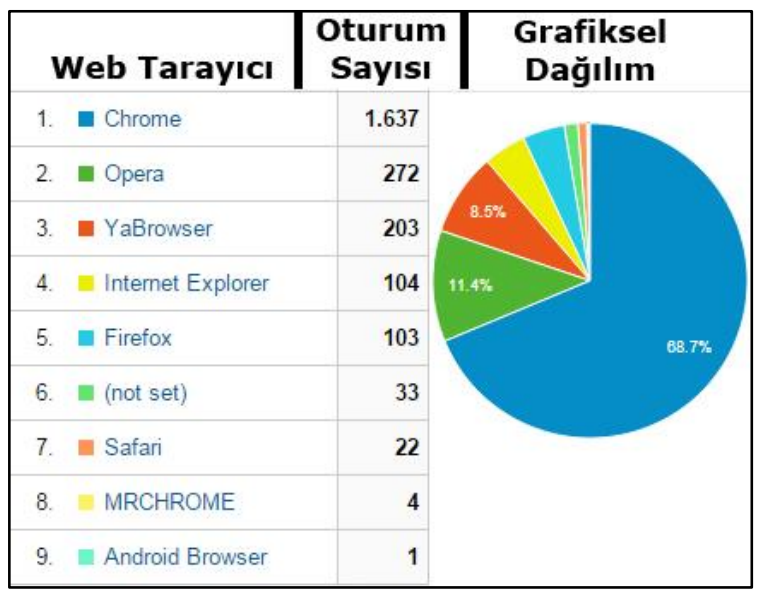

Şekil 4. "4" Numaralı web sayfasına erişimde kullanılan web tarayıcıları

Tablo 2. Web tarayıcı sürümlerine göre değişen CSS özellikleri (X uyumsuz, $\checkmark$ uyumlu) [5]

(Changing CSS properties, according to the Web browser version $(X$ incompatible, $\checkmark$ compatible))

\begin{tabular}{|l|l|l|}
\hline CSS Özelliği & Internet Exporer 8 & Internet Exporer 9 \\
\hline border-radius & X & $\checkmark$ \\
\hline box-shadow & X & $\checkmark$ \\
\hline transform & X & $\checkmark$ \\
\hline transition & X & X \\
\hline placeholder & X & X \\
\hline
\end{tabular}

Web sayfalarına erişim yapan kullanıcıların, web sayfasına erişim sağlarken kullandıkları web tarayıcının farklı olmasının yanında kullanıcıların ekran çözünürlükleri de birbirinden farklıdır. Bu farklılık sabit çözünürlük ayarı ile tasarlanan ve kullanıma sunulan web sayfalarında çeşitli problemlere neden olmaktadır. Kullanıcıların hepsi standart bir çözünürlük değeri kullanmamaktadır. Şekil 5.'te farklı çözünürlüklere sahip ekranlardan web sayfalarına yapılan erişimler gösterilmiştir. Şekil 5.'te örnek olması açısından Tablo 1'de gösterilen 2. web sayfasına erişim sağlayan kullanıcıların ekran çözünürlüklerinin bilgisi verilmiştir.

\begin{tabular}{|c|c|c|}
\hline $\begin{array}{c}\text { Ekran } \\
\text { Çözünürlügüü }\end{array}$ & $\begin{array}{c}\text { Oturum } \\
\text { Sayısı }\end{array}$ & $\begin{array}{c}\text { Grafiksel } \\
\text { Dağılım }\end{array}$ \\
\hline 1. (not set) & 1.025 & \\
\hline 2. $1366 \times 768$ & 326 & \\
\hline 3. $1280 \times 1024$ & 174 & \\
\hline 4. $=360 \times 640$ & 149 & \\
\hline 5. $=320 \times 568$ & 90 & \\
\hline 6. $=720 \times 1280$ & 71 & \\
\hline 7. $1024 \times 768$ & 66 & \\
\hline 8. $1280 \times 800$ & 54 & \\
\hline 9. $1440 \times 900$ & 53 & \\
\hline 10. $1920 \times 1080$ & 49 & \\
\hline
\end{tabular}

Şekil 5. "2." web sayfasına erişim sağlayan kullanıcıların ekran çözünürlük bilgileri 
Şekil 5'te web sayfasına erişimin sağlandığı ekranın çözünürlük değerlerinin farklılık gösterdiği izlenmektedir. Sabit çözünürlük değerine göre tasarlanan web sayfaları bu farklı çözünürlük değerleri ile düzgün şekilde görüntülenemeyecektir. Bu durum kullanıcının işini zorlaştırmakta ve web sayfalarının kullanım kolaylığını negatif yönde etkilemektedir.

Yapılan araştırma ve çalışmalar sonucu web sayfaları veya web uygulamalarına farklı cihazlardan, farklı web tarayıcılarından, farklı web tarayıcıları sürümlerinden ve farklı ekran çözünürlügüne sahip ortamlardan erişimin sağlandığı açıkça görülmektedir. Bu farklılık sabit çözünürlük ve CSS özelliklerine sahip olacak şekilde geliştirilen web sayfaları veya web uygulamalarında problemlere neden olmaktadır. Kullanıcı istediği web sayfa alanını net olarak görememekte, CSS özellikleri birbirinin üzerine binmektedir. Dolaysıyla bu çalışmada belirtilen probleme çözüm üretmek amacıyla duyarlı web sayfa tasarımı önerilmiş ve bir M2M platformu üzerinde gerçekleştirilmiştir. Bu sayede her işletim sistemi veya her mobil ortam için ayrı ayrı uygulama geliştirmenin önüne geçilmeye çalışılmıştır. Geliştirilen duyarlı tasarıma sahip M2M platformuna kullanıcılar, her tür cihaz ve web tarayıcıdan sorunsuz bir şekilde ulaşabilmektedir.

\section{UYGULAMA GELIŞTIRME (APPLICATION DEVELOPMENT)}

$\mathrm{Bu}$ çalışma kapsamında M2M web platformu için duyarlı tasarıma sahip bir arayüz geliştirilmiştir. Platformun arayüzü Hiper-Metin İşaretleme Dili (HTML: Hypertext Markup Language) sürüm 5 ve CSS sürüm 3 kullanılarak hazırlanmıştır. Dinamik tabloların oluşturulması gibi durumlarda ise bir javascript kütüphanesi olan JQUERY kullanılmıştır. Özellikle hareketli görseller JQUERY ile desteklenmiştir. Ana yapının oluşturulmasında açık kaynak kodlu bir CSS framework olan ve javascript kodları ile desteklenen Bootstrap kullanılmıştır.

Bootstrap HTML sürüm 5 için geliştirilmiş bir framework olup HTML’i daha düşük sürümlerinde çalışmamaktadır. Çünkü HTML5 sürümü geliştiricilere standart başlıklar sunmaktadır. Hazırlanan bir HTML web sayfasında HTML5 kodlarının kullanılması için <!DOCTYPE html $>$ kod satırının HTML sayfasının en üstüne yerleştirilmesi gerekmektedir. Ardından ise $<h t m l>$ başlığ 1 içerisinde hazırlanan web sayfasinın dil kodu girilmelidir.

Ana yap1 oluşturulduktan sonra $<$ HEAD $>$ bölümünün düzenlenmesi gerekmektedir. Bu kısımda kullanılan CSS ve javascript dosyaları sisteme eklenmelidir. Yine aynı bölüm içerisinde web sayfasının duyarlı bir yapıya sahip olması için bir meta etiketi yerleştirilmelidir.

$<$ meta name="viewport" content="..." />

Meta yapısı içerisinde bulunan "viewport" etiketi kullanıcının cihazındaki görüntülenme alanı olarak tanımlanabilmektedir. Web sayfasının genişliği viewport'a göre anlık olarak hesaplanmaktadır. Masaüstü bilgisayarda bu genişlik, web tarayıcısının genişliğine eşittir. Fakat mobil web tarayıcılarında bu durum biraz daha karmaşıktır. Farklı mobil cihazlarının farklı ekran özelliklerine sahip olduğu bir gerçektir. Bu durumda fiziksel bir piksel değeri yerine CSS pikselleri ile çalışmak daha iyi sonuç verecektir.

Viewport etiketinin "content" bilgisinin içerisinde tanımlanabilecek sabit genişlikten zoom özelliğine kadar birçok özellik mevcuttur. Etiketi içerisinde tanımlanan "width=device-width" özelliği ile web sayfasının genişliği, cihazın ideal ekran genişliği için otomatik olarak ayarlanmaktadır. Böylelikle görüntülenme alanı ekranı büyütmeye gerek kalmadan ideal bir boyutta kullanıcıya sunulmaktadır. Bazı geliştiriciler ideal görüntülenme alanına ek olarak "viewport" etiketi "content" bilgisinin içerisinde "initial-scale" değerini de kullanmaktadır. Bu kullanımın amacı başlangıçta kullanıcıya sunulan ekran büyütme/küçültme oranı (zoom) miktarının belirlenmesidir. İdeal görüntülenme alanına göre ayarlanan bu değer "initial-scale=1" olarak verildiğinde web sayfası için hazırlanan özel görünüm alanlarını ideal görüntülenme alanına eşdeğer yapacaktır. Ayrıca yine bu etiket sayesinde kullanıcının web sayfasını en fazla kaç kez büyüteceği de belirtilebilmektedir.

Web tarayıcıların hepsi aynı özelliklere sahip olmadığı gibi hepsi aynı CSS özelliklerini de desteklememektedir. Bu nedenle duyarlı tasarıma sahip web sayfaları geliştirilirken web tarayıcılarının özellikleri iyi bilinmelidir. Örneğin Safari web tarayıcısı duyarlı bir tasarımla geliştirilen ve aşağıdaki kod yapısını kullanan web sayfalarında hata vermektedir. 
<meta name="viewport" content="width=device-width" />

Belirtilen kod yapısı kullanılarak geliştirilen web sayfasının Safari web tarayıcısında açıldığında duyarlı bir tasarıma sahip olmadığı açıkça görülecektir. Bunun nedeni ise Safari web tarayıcısının görüntülenme alanı olarak Apple Iphone ve Ipad cihazlarını temel alması ve farklı cihazların genişlik bilgilerini içermemesidir. Bazı durumlarda ise Internet Explorer web tarayıcısı duyarlı tasarıma sahip web sayfalarında, Safari web tarayıcısının aksine davranış izleyip aynı kod yapısı kullanıldığında hata vermektedir. Bu nedenle duyarlı tasarımla gerçekleştirilmek istenen web sayfalarında meta etiketi olarak kullanılması gereken en sağlıklı kod yapısı şu şekildedir.

<meta name="viewport" content="width=device-width, initial-scale=1, maximum-scale=1" />

Belirtilen kod yapısı web arayüzü geliştirilmesinde kullanıldığında, web sayfasının açıldığı ekran çözünürlük bilgileri kullanıcının sisteminden alınarak duyarlı görünüm oluşturulur. Fakat bu meta etiketinin kullanılması tek başına yeterli değildir. Bazı durumlarda bu etiketin CSS ile desteklenmesi gerekir. CSS özelliklerinden biri olan "media" web sayfalarından çıktı alınırken kullanılmaktadır [18]. Fakat CSS sürüm 3 ile beraber "media" özelliğine yeni yetenekler eklenmiş̧tir. CSS 3 "media" özelliği bir veya daha fazla tipe göre sorgulama yapmakta ve sorgunun doğruluğuna göre o CSS dosyasını uygulamaktadır [19]. Özetle CSS "media” özelliği, farklı durumlarda farklı CSS özelliklerini aktif hale getirmektedir. Böylelikle hangi çözünürlükte veya ekran boyutunda web sayfası açılıyorsa o çözünürlüğe veya ekran boyutuna ait CSS özellikleri çalışmaktadır. CSS “media” özelliğinin kullanımı şekil 6'da gösterilmektedir.

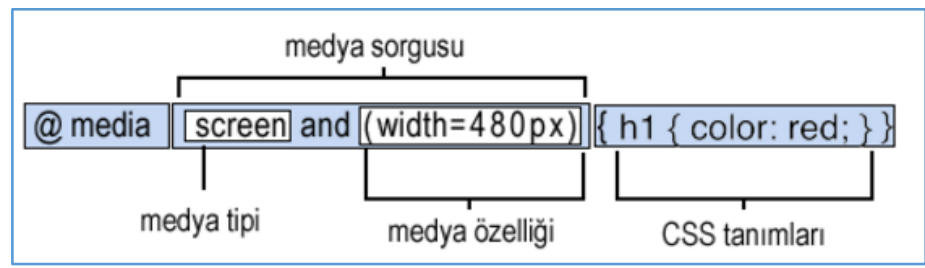

Şekil 6. Duyarlı tasarım için gerekli CSS “media” özelliğinin kullanımı [19]

Şekil 6'da gösterilen "media" özelliği CSS doyasının içerisine yazılır. Medya tipinde belirtilen "screen" ile görüntülemenin mobil cihazlar haricindeki sistemlerde olacağı belirlenir. Ayrıca bu alanda televizyonlarda, el bilgisayarlarında yazıcı çıktılarında vb. yerlerde görüntüleneceği seçilebilir. CSS "media" özelliğinde ayrıca ekran genişlik değeri belirlenip bu genişlik elde edildiğinde işleme alınması gereken CSS özellikleri tanımlanabilir. Örneğin ekran genişlik değerinin 480px olduğu durumda HTML "h1" etiketinin kırmızı olmasını sağlayan kod yapısı şekil 6'da verilmiştir. HTML "h1" etiketine ait CSS özellikleri "media" etiketinin CSS tanımları bölümünde verilmiştir. Bu çalışma kapsamında geliştirilen M2M platform arayüzünde dört farklı çözünürlük değeri için CSS “media” sorguları geliştirilmiştir.

- @media (max-width: 767px)

- @media (min-width: 768px)

- @ media screen and (min-width: 768px)

- @ media screen and (min-width: 992px)

CSS “media” sorguları incelendiğinde, M2M platformu geliştirilirken değişen ekran genişlik değerlerinin göz önüne alındığı net bir şekilde görülmektedir. En çok 767px'den aşağı olan genişlik değerlerinde ve en az 768px olan genişlik değerlerinde hangi CSS özelliklerinin değiştirileceği M2M platform arayüzü geliştirilirken belirtilmiştir. Ayrıca "screen" özelliğinin en az 768px ve en az 992px değerleri ile birlikte kullanıldığ1 görülmektedir. Bu kullanım ile web sayfasına bilgisayar üzerinden erişim sağlandığı belirtilmekte olup en az olabilecek genişlik değerleri verilmiştir. Böylelikle M2M platformuna erişimin ne kadar ekran genişlik değerine sahip bir sistemden sağlandığı bulunmakta olup o genişlik değerine göre M2M platform arayüzlerinin dinamik bir şekilde değiştirilmesi sağlanmıştır.

Bu çalışmada, web tabanlı bir M2M platformu geliştirilirken duyarlı tasarıma sahip olması açısından gerekli yöntemler detaylı olarak anlatılmıştır. Bu aşamadan sonra ise web sayfasının nasıl tasarlanacağı geliştiricilerin becerilerine bırakılmıştır. HTML 5 ve CSS 3 sürümlerinin mükemmel uyumu kullanılarak 
geliştirilen web sayfaları daha dinamik ve daha düzgün çalışabilmektedir. Bu nedenle geliştiricilere duyarlı tasarıma sahip web sayfaları geliştirilirken bu yapıları kullanması ve kesinlikle CSS pikseli dışında fiziksel bir piksek değerinin kullanılmaması önerilmektedir.

\section{TEST İŞLEMLERİ (TEST PROCEDURES)}

Duyarlı tasarıma sahip web sayfalarını test etmek için birçok araç bulunmaktadır. Bu test araçlarından en yaygın kullanılanı Google Chrome web tarayıcısıdır. Chrome geliştiricilere cihaz modu ve mobil emülasyon araçlarını ücretsiz olarak sunmaktadır. Chrome'un sağladığı bu araçlar sayesinde, geliştirilen ve duyarlı tasarıma sahip olan bir web sayfasının farklı cihazlarda doğru görünüme sahip olup olmadığı rahatlıkla test edilebilmektedir. Bu çalışmada geliştirilen M2M platformu arayüzleri hem Chrome üzerinde hem de fiziksel diğer ortamlarda (akılll telefon, tablet, dizüstü bilgisayar) test edilmiș ve bașarılı sonuçlar alınmıştır. Geliştirilen M2M platform arayüzleri farklı akıllı telefonlarda şekil 7'deki gibi bir görünüme sahiptir.

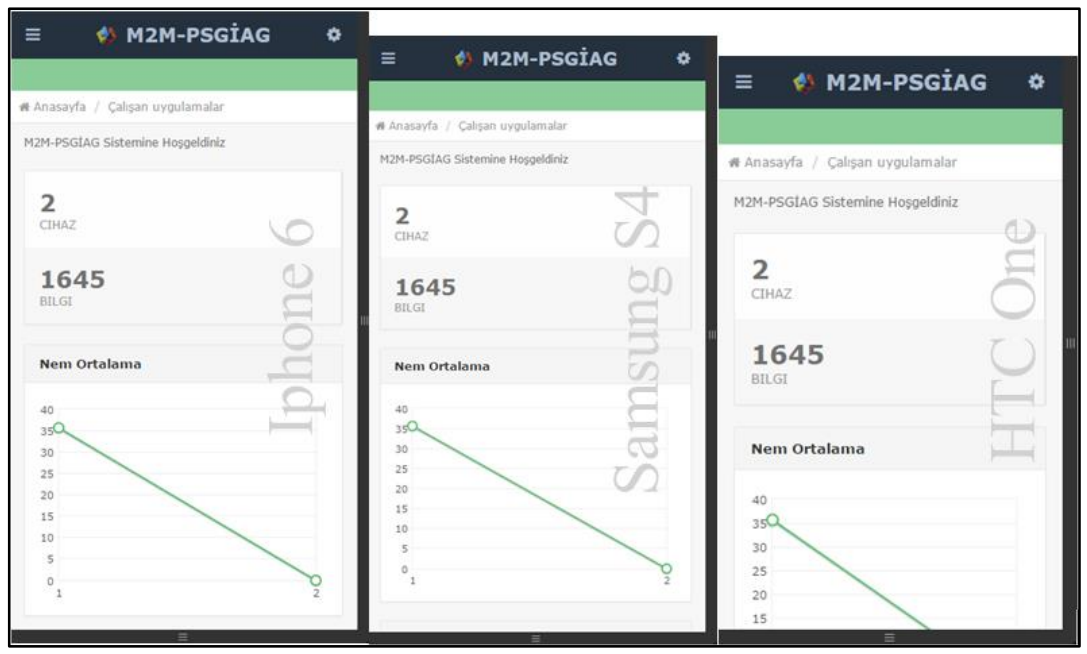

Şekil 7. Geliştirilen M2M platform web arayüzünün akıllı telefonlarda görünümü

Şekil 7'de görüldügü gibi geliştirilen M2M platform arayüzleri, erişim sağlanan akıllı telefonun ekran boyutuna göre kendini dinamik bir șekilde ayarlamaktadır. Test işlemleri farklı akıllı telefonlarda yapıldığı gibi farklı tarayıcı ve farklı tablet, masaüstü ve dizüstü PC ortamlarında da yapılmış ve başarılı sonuçlar alınmıştır.

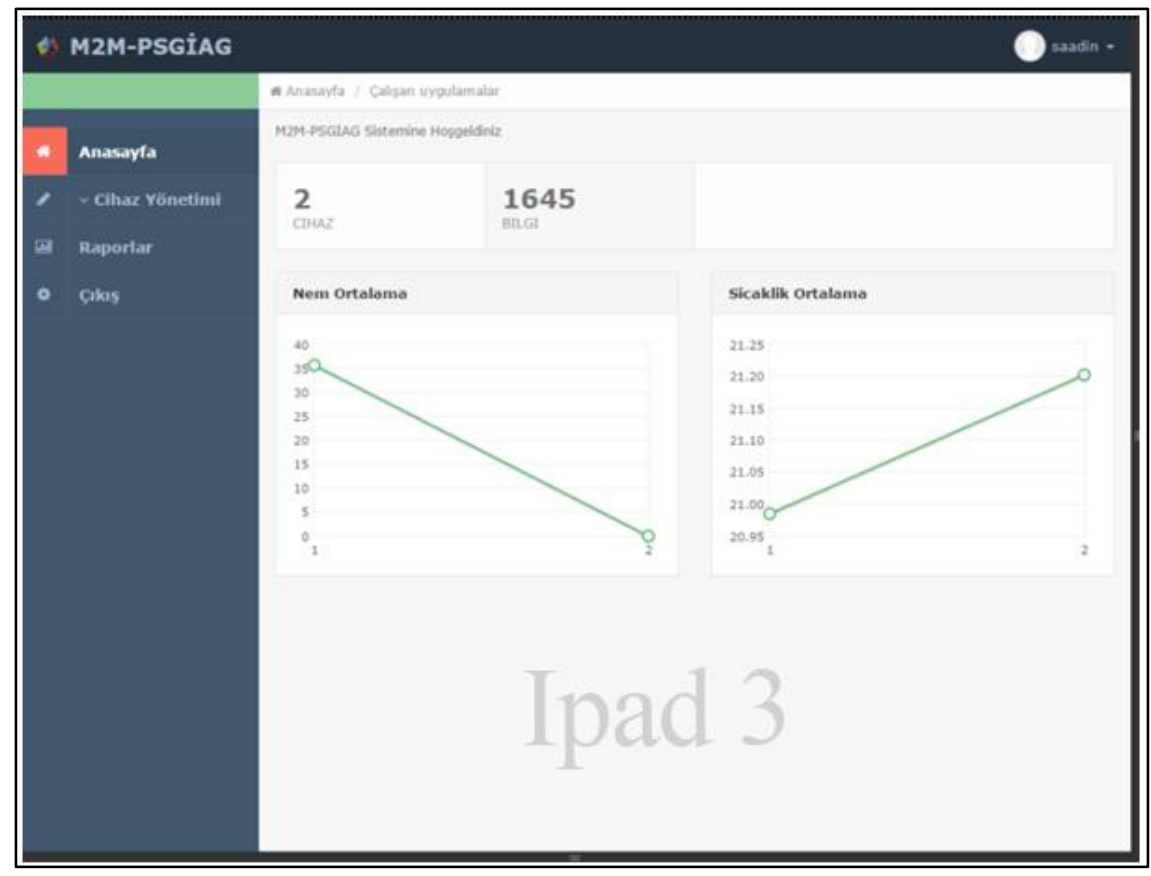


Şekil 8. Geliştirilen M2M platformunun Apple Ipad3 tablet cihazlarda görünümü

Apple Ipad3 tablet cihazında geliştirilen M2M platformunun web arayüz görünümü şekil 8'de verilmiştir. Şekil 8'de görüldüğü gibi M2M platformu düzgün ve net bir görünüme sahiptir. Yapılan testler sonucu M2M platform arayüzlerinin Internet Explorer sürüm 9'un altındaki sürümlerinde düzgün çalışmadığ1 görülmüştür. Bu sorunu giderebilmek için javascript yardımı ile yapılmış çeşitli yöntemler mevcuttur. Fakat bu çalışmada geliştirilen M2M platformunda, bu problem Jquery ile oluşturulan bir yöntem sayesinde giderilmiştir. Bu yöntemde öncelikle Internet Explorer sürümü tespit edilmekte ve duyarlı tasarım için gerekli özellikler Internet Explorer'e kazandırılmaktadır. Bu sayede sorunsuz çalışabilen duyarlı tasarıma sahip bir M2M platform arayüzü geliştirilmiştir.

\section{SONUÇ (CONCLUSION)}

$\mathrm{Bu}$ çalışmada, internete bağlanabilen herhangi bir cihaz üzerindeki web tarayıcısında sorunsuz olarak görüntülenebilen, duyarlı tasarıma sahip, web tabanlı bir M2M platform arayüzü geliştirilmiştir. Geliştirilen M2M uygulamalarının kullanıcı ile etkileşime geçebilmesi için gerekli olan M2M platformlarının farklı bir bakış açısıyla ele alındı̆̆ bu çalışma, yalnızca özel bir alana değil değişik M2M uygulamalarına entegre edilebilir niteliktedir. Geliştirilen M2M platform arayüzü, sayıları gittikçe artan mobil cihazlarda ve aynı zamanda diğer erişim cihazlarında sorunsuz çalışabilmektedir. Web tabanlı olarak geliştirilen platforma, web tarayıcılarının çalışabildiği her ortamdan sorunsuz olarak ulaş1labilmektedir. Böylelikle mobil cihazlar için geliştirilen mobil uygulamalara veya mobil sitelere gereksinim ortadan kaldırılmışıı. Duyarlı bir tasarımla geliştirilen M2M platform arayüzü sayesinde mobil cihazlardan rahatlıkla M2M platformuna erişim sağlanmıştır. Web arayüzlerinin duyarlı tasarım ile geliştirilmemesi durumunda farklı çözünürlük değerlerine sahip sistemlerde web sayfaları düzgün görüntülenmeyecek ve kullanımı zorlaşacaktır. Duyarlı tasarıma sahip M2M platform arayüzü, kullanıcılara kullanım kolaylığı sağlamaktadır. Ayrıca arayüz geliştiricilerini her mobil işletim sistemi için ayrı ayrı mobil uygulama oluşturma zahmetinden kurtarmaktadır. Bu sayede zaman ve maliyet tasarrufu elde edilmektedir.

\section{KAYNAKLAR (REFERENCES)}

[1] Y. Yang, H. Ye, S. Fei, "Design of communication interface for M2M-based positioning and monitoring system", In Electronics, Communications and Control (ICECC), 2011 International Conference on (pp. 2624-2627), IEEE, September, 2011.

[2] B. Zhu, "Responsive design: E-learning site transformation", In 2013 Fourth International Conference on Networking and Distributed Computing (ICNDC), (pp. 126-130), IEEE. December, 2013.

[3] N. Rogatnev, Responsive Web Design, Master Thesis, MAMK, Helsinki, 2015.

[4] S. Mohorovicic, "Implementing responsive web design for enhanced web presence", In Information \& Communication Technology Electronics \& Microelectronics (MIPRO), 36th International Convention on (pp. 1206-1210), IEEE. May, 2013.

[5] W. Jiang, M. Zhang, B. Zhou, Y. Jiang, Y. Zhang, "Responsive web design mode and application", In IEEE Workshop on Advanced Research and Technology in Industry Applications, 2014.

[6] M. H. Baturay, M. Birtane, "Responsive web design: A new type of design for web-based instructional content". Procedia-Social and Behavioral Sciences, 106, 2275-2279, 2013.

[7] C. J. Hughes. M. Armstrong, R. Jones, M. Crabb, "Responsive design for personalised subtitles. In Proceedings of the 12th Web for All Conference (p. 8). ACM. May, 2015.

[8] M. Baytürk, G. Çetin, A. Çetin, "Gömülü Sunucu ile Tasarlanmış İnternet Tabanlı Sera Otomasyon Sistemi Uygulaması”, International Journal Of Informatics Technologies, 6(2), 53, May1s, 2013. 
[9] C. Doukas, I. Maglogiannis, "Managing Wearable Sensor Data Through Cloud Computing", In Cloud Computing Technology and Science (CloudCom), IEEE Third International Conference on (pp. 440445), IEEE, November, 2011.

[10] E. J. Kim, S. Youm, "Machine-to-Machine Platform Architecture For Horizontal Service Integration", EURASIP Journal on Wireless Communications and Networking, (1), 1-9, 2013.

[11] J. Song, A. Kunz, M. Schmidt, P. Szczytowski, "Connecting and Managing M2M Devices in The Future Internet”, Mobile Networks and Applications, 19(1), 4-17, 2014.

[12] H. Takatsuka, S. Saiki, S. Matsumoto, M. Nakamura, "Design and implementation of rule-based framework for context-aware services with web services", In Proceedings of the 16th International Conference on Information Integration and Web-based Applications \& Services, (pp. 233-242), ACM, December, 2014.

[13] M. B. Alaya, Y. Banouar, T. Monteil, C. Chassot, K. Drira, "OM2M: Extensible ETSI-compliant M2M Service Platform with Self-configuration Capability", Procedia Computer Science, 32, 10791086, 2014.

[14] F. Jammes, H. Smit, "Service-Oriented Paradigms in Industrial Automation". Industrial Informatics, IEEE Transactions on, 1(1), 62-70, 2005.

[15] Y. Inal, N. Ö. Çınar, K. Çağıltay, "Kamu İnternet Sitelerinde Yer Alan Arama Alanlarının Kullanılabilirliği ve Buna Yönelik Kullanıcı Davranışlarının Belirlenmesi”, International Journal Of Informatics Technologies, 9(1), 41, 2016.

[16] V. Ates, H. Karacan, "Abant İzzet Baysal Üniversitesi Web Sitesi Kullanılabilirlik Analizi”, International Journal of Informatics Technologies, 2(2), 2009.

[17] B. Plaza, "Google Analytics for Measuring Website Performance",Tourism Management, 32(3), 477-481, 2011.

[18] E. Harb, P. Kapellari, S. Luong, N. Spot, Responsive Web Design, Version of 06, December, 2011.

[19] İnternet: F. Hayrioğlu, CSS Medya Sorguları, http://fatihhayrioglu.com/css-3-medya-sorgulari/, 16.02.2016. 